\title{
MAPA DOS PRODUTORES BRASILEIROS DE BIOCOMBUSTÍVEIS PELLETS
}

BIOENG

D. P. Garcia ${ }^{1 *}$, J. C. Caraschi ${ }^{1}$, E. A. Dal Bem ${ }^{2}$, J. P. Ferreira ${ }^{3}$,

${ }^{1}$ UNESP - Universidade Estadual Paulista, Itapeva, SP, Brasil

${ }^{2}$ FAIT - Faculdade de Ciências Sociais e Agrárias, Itapeva, SP, Brasil

${ }^{3}$ UNIFIPA - Centro Universitário Padre Albino, Catanduva, SP, Brasil

Article history: Received 30 May 2018; Received in revised form 19 September 2018; Accepted 12 October 2018; Available online 19 December 2018.

\section{RESUMO}

Os pellets são biocombustíveis que podem ser produzidos a partir de resíduos lignocelulósicos como o bagaço da cana-de-açúcar, serragem ou maravalha de madeira. A demanda mundial por esses produtos cresce exponencialmente, porque são recursos energéticos de baixo carbono e são utilizados por países que precisam reduzir suas emissões de gases do efeito estufa para atender aos acordos firmados na COP21. Para explorar as oportunidades desse negócio promissor é preciso oferecer informações ao mercado a respeito da produção, quantidade de indústrias produtoras e quais materiais lignocelulósicos estão sendo compactados no formato de pellets. Para isso, este artigo quer elaborar um mapa on line dos produtores de pellets brasileiros, descobrir qual tipo de biomassa vegetal é utilizada como matéria-prima e apurar quanto o país produziu desse biocombustível em 2017. Uma pesquisa com os atuais produtores foi realizada, com aplicação de um formulário on line do Google Forms, que obteve $100 \%$ de índice de resposta. Com base nesses dados construiu-se um Mapa dos Produtores Brasileiros de Pellets. Os resultados revelaram 18 fábricas ativas, distribuídas em cinco estados, que produziram 470 mil toneladas do produto em 2017, fabricados a partir de pinus, acácia-negra, bagaço de cana-de-açúcar e casca de café.

Palavras-chave: biomassa, energia renovável, pinus, bagaço-de-cana, Acacia mearnsii.

\section{MAP OF BRAZILIAN BIOFUELS PRODUCERS PELLETS}

\begin{abstract}
Pellets are biofuels that can be produced from agroforestry waste such as sugarcane bagasse, sawdust or wood shavings. Global demand for these products grows exponentially because they are low-carbon energy resources and are used by countries that need to reduce their greenhouse gas emissions to meet the agreements reached at COP21. To explore the opportunities of this promising business, it is necessary to provide information to the market regarding the production, quantity of producing industries and which lignocellulosic materials are being compacted in pellet format. To do this, this article wants to draw up an online map of Brazilian pellet producers, to find out what kind of plant biomass is used as raw material and to determine how much the country produced from this biofuel in 2017. A research with producers was carried out, with application of a Google Forms online form, which obtained a $100 \%$ response rate. Based on these data a Map of Brazilian Pellet Producers was constructed. The results revealed 18 active industries, distributed in five states, that produced 470 thousand tons of the product in 2017, made from pine, black acacia, sugar cane bagasse and coffee husks.
\end{abstract}


Keywords: biomass, renewable energy, pinus, sugarcane bagasse, Acacia mearnsii.

\section{INTRODUÇÃO}

O Brasil é considerado um gigante global em termos de produtividade de matérias-primas de biocombustíveis. Por conta de suas características edafoclimáticas propícias para a produção de biomassas vegetais, possui potencial para aproveitar ainda mais esses recursos energéticos, especialmente nas questões ligadas à produção de combustíveis sólidos na forma de pellets (SCATOLINO et al., 2017). Este mercado é considerado como uma promissora oportunidade comercial com a Europa, devido à sua proximidade continental e crescente demanda por esse biocombustível sólido (WELFLE, 2017).

A demanda mundial por pellets cresce exponencialmente, assim como as previsões de consumo desse biocombustível (Figura 1), pois eles são menos poluentes que os derivados de petróleo e são utilizados por países que precisam reduzir suas emissões de gases do efeito estufa e atender aos acordos firmados na Conferência do Clima (COP21), que ocorreu na França, em 2015 (GARCIA et al., 2016a; TAVARES \& TAVARES, 2015; THRÄN et al., 2017).

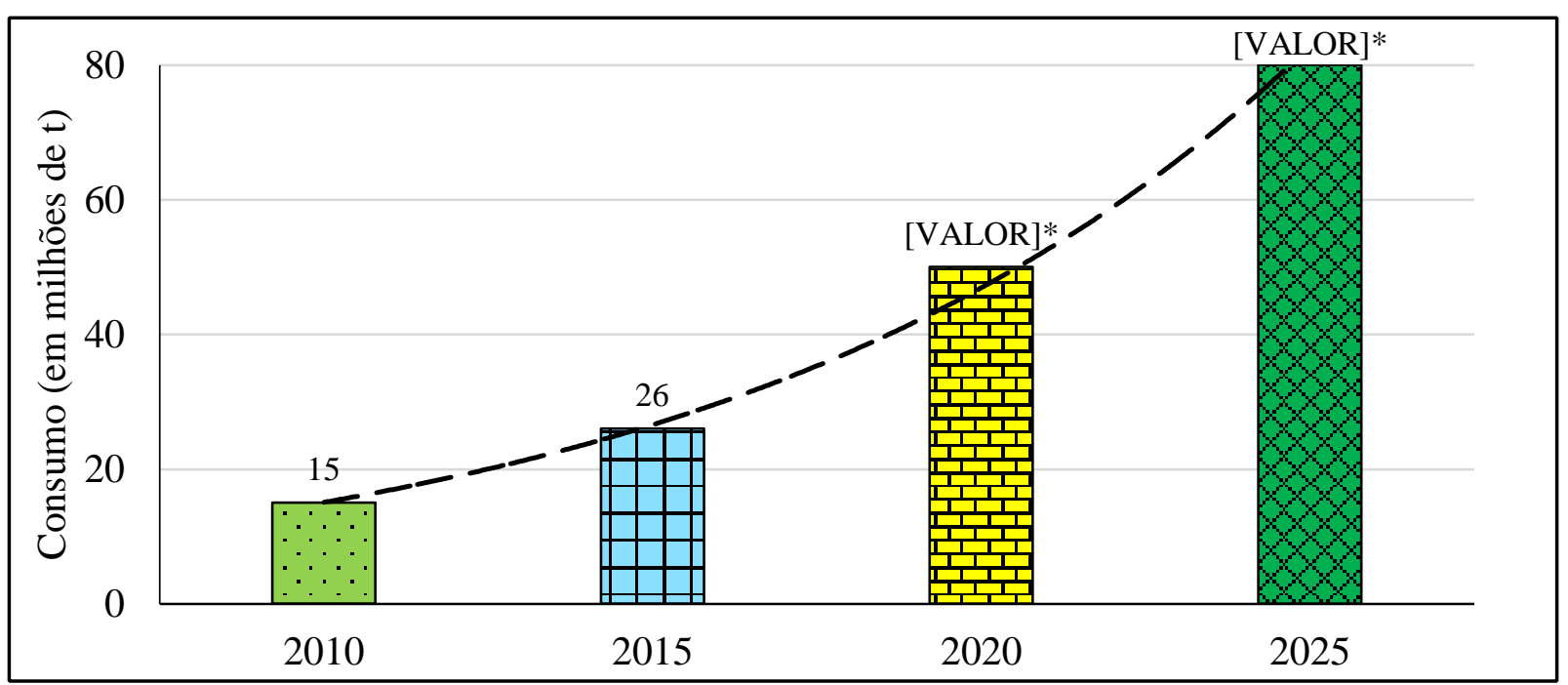

Figura 1. Evolução mundial do consumo de pellets e as previsões para os próximos anos $(*)$.

Os pellets são combustíveis renováveis produzidos a partir de resíduos agroflorestais (pó de serra, serragem e maravalha de madeira, bagaço de cana) que passam por processo de secagem (umidade ideal de 12\%), moagem (tamanho de partículas $\approx 3,0 \mathrm{~mm}$ ) $\mathrm{e}$ densificação em matriz peletizadora perfurada com abertura de 6 ou $8 \mathrm{~mm}$ de diâmetro (GARCIA et al., 2016a; 2018). Esses biocombustíveis sólidos são commodities comercializadas internacionalmente, que possuem baixo teor de umidade (5-10\%), permitindo elevada densidade energética (11-14 $\mathrm{GJ} / \mathrm{m}^{3}$ ), que se traduz em eficiência térmica nas conversões de energia e baixo custo no transporte à longas distâncias. Sua geometria cilíndrica regular permite ótima fluidez e facilita a automatização de processos (residenciais, comerciais e industriais) de queima do produto em equipamentos industriais. Além disso, por ser material compactado e denso, é um produto de fácil manuseio que ocupa pouco espaço de armazenagem (CHRISTOFOROU \& FOKAIDES, 2017; SPANHOL et al., 2015; TAVARES \& TAVARES, 2015).

A produção de pellets no Brasil cresceu nos últimos anos. Em 2015 e 2016, o país produziu 75,0 e 135,35 mil toneladas do produto, respectivamente (GARCIA, 2017; GARCIA et al., 2017). Esses autores relatam que o Brasil sempre é apontado como uns dos principais atores 
neste segmento de biomassa agroflorestal para energia, e por isso, cresceu a necessidade de se ter números e dados mais confiáveis desse mercado de energia renovável e dessa nova economia de baixo carbono.

Assim, esse estudo é importante porque, para explorar as oportunidades desse negócio (produção e comercialização), é preciso oferecer informações ao mercado a respeito da produção, quantidade de indústrias, mercado consumidor e materiais agroflorestais que estão sendo utilizados

\section{METODOLOGIA}

\section{Formulários da pesquisa}

Para obter os resultados aplicou-se um questionário, desenvolvido por meio do recurso de formulários on line do Google Forms. Optou-se por utilizar este recurso por sua facilidade de distribuição, preenchimento e apuração dos resultados. Além disso, Heidemann et al. (2010) apontaram outras vantagens desses formulários: baixo custo (porque é gratuito), facilidade de uso (porque não requer conhecimentos específicos) e interface amigável e fácil de usar (porque são semelhantes aos aplicativos usuais).

Um convite com o link do formulário com as perguntas foi enviado, via e-mail, à todos os produtores de pellets do Brasil. Para impedir que $o$ formulário fosse editado, modificado, apagado ou compartilhado inadvertidamente, essas funções foram bloqueadas. Todas as perguntas exigiam respostas obrigatórias que impediam o envio parcial do formulário. As perguntas foram elaboradas de dois tipos diferentes: (a) tipo texto, para questões dissertativas abertas; (b) múltipla escolha, para selecionar somente uma das opções apresentadas.

A pesquisa de campo foi realizada entre os meses de janeiro e março de 2018 e iniciou-se com o envio de um link do formulário para as empresas produtoras de biocombustíveis pellets do Brasil. $\mathrm{O}$ formulário apresenta três perguntas sobre $\mathrm{o}$ mercado de pellets no Brasil: (1) solicita para a produção dos pellets. Com estas informações, possíveis empresários, desenvolvedores de equipamentos e consumidores do produto renovável terão mais confiança no mercado para investir nesse novo recurso energético.

Portanto, este artigo tem a intenção de fornecer um mapa dos produtores brasileiros de pellets, descobrir quais materiais lignocelulósicos são utilizados como matéria-prima e apurar quanto o país produziu desse biocombustível sólido no ano de 2017.

informações básicas da empresa; (2) pergunta qual a produção de pellets no ano de 2017; (3) pergunta qual a matéria-prima utilizada na produção dos pellets. Das dezoito empresas cadastradas como fabricantes do produto, somente duas não responderam às perguntas, mas suas principais informações foram obtidas, posteriormente, via telefone fixo. Assim, dado o método de aplicação do questionário e a dispersão dos fabricantes de pellets pelas diversas regiões do Brasil, obteve-se um satisfatório índice de resposta de $100 \%$.

\section{Uso da ferramenta do Google Maps}

Para a criação do Mapa dos Produtores Brasileiros de Pellets, utilizouse a plataforma gratuita do Google Maps. Trata-se de um serviço, lançado em 2005, que permite a criação de mapas personalizados e diversificados, com posterior possibilidade de compartilhamento com outros usuários (HU \& DAI, 2013). A interface do programa é simples e fornece livre acesso a informações de mapas e satélites, permitindo o conceito de localização espacial e distância entre os lugares (HSU et al., 2012). A escolha deste aplicativo se deu por ser uma plataforma livre, gratuita, altamente integrada aos smartphones e por não precisar de nenhum programa para executá-lo, pois tudo é construído por meio 
do aplicativo on line (SILVA \& CHAVES,

2011).

\section{RESULTADOS E DISCUSSÃO}

Com base nas análises das respostas dos formulários, pode-se fazer inferências de interesse sobre a produção e o mercado de pellets no Brasil e atingir os objetivos traçados para este estudo. As informações básicas das empresas, solicitadas no formulário, serviram de base para a criação do Mapa dos Produtores Brasileiros de
Pellets, mostrados na Figura 2. Usando os recursos interativos do Google Maps, localizou-se o endereço da empresa e um marcador colorido foi adicionado junto ao seu nome de fantasia, com endereço físico, telefone e e-mail, objetivando facilitar o contato dos consumidores com os produtores desses biocombustíveis sólidos.

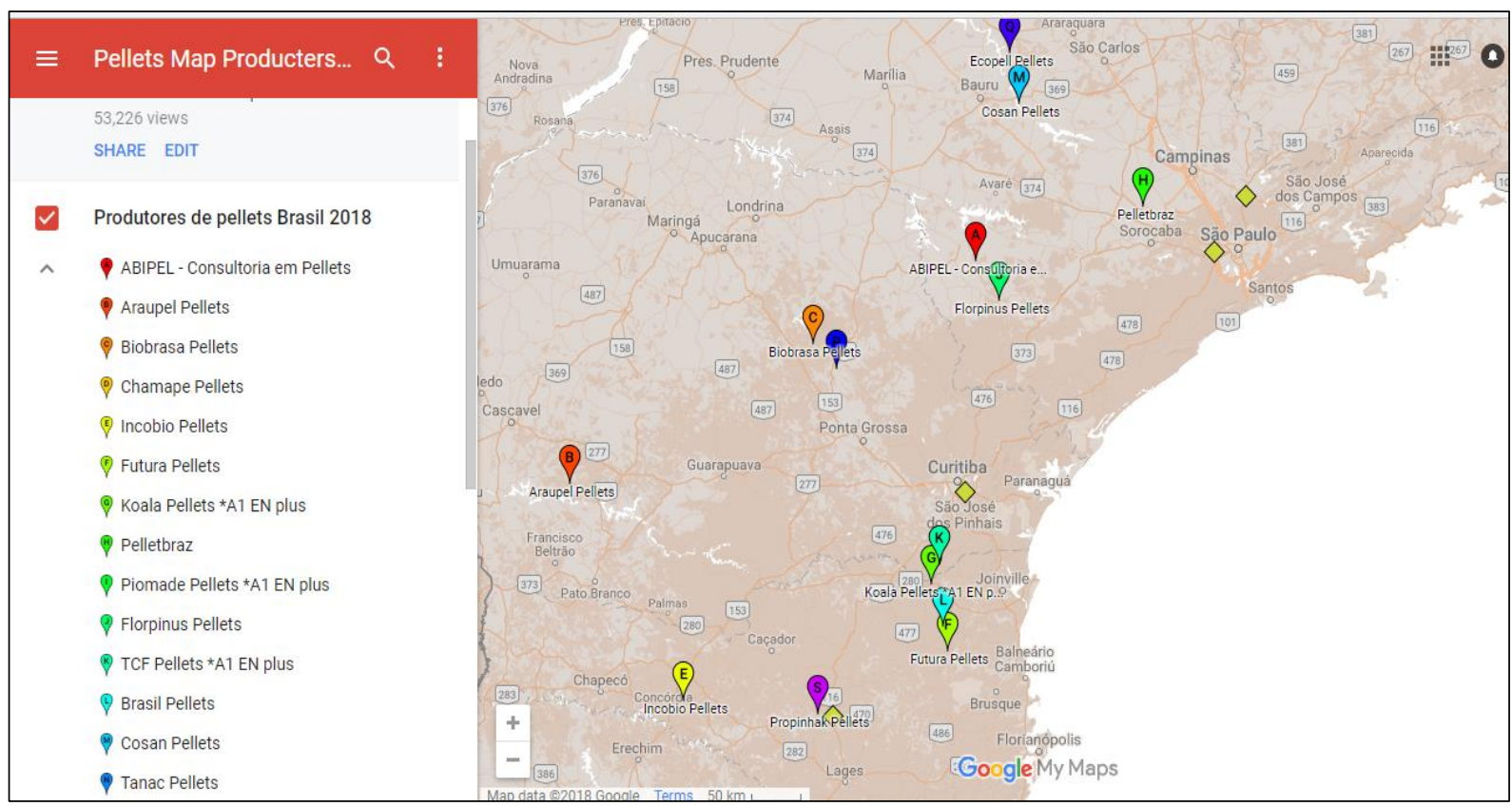

Figura 2. Mapa dos produtores Brasileiros de Pellets de biomassa vegetal, no ano de 2017.

A ideia da criação do mapa é facilitar a aquisição dos biocombustíveis por consumidores de todo o Brasil, uma vez que ele poderá localizar facilmente a fábrica mais próxima para a compra do produto. Além disso, o mapa facilita o comércio, contribui para ampliar o consumo e favorece o conhecimento das vantagens da utilização dos pellets, impulsionando a demanda interna por esses biocombustíveis sólidos. Esses problemas mercadológicos (baixo consumo interno e desconhecimento das características do produto) são apontados como os mais relevantes para o lento desenvolvimento do mercado interno dos pellets no país (GARCIA et al., 2017; TAVARES \& TAVARES, 2015).

O Mapa dos produtores Brasileiro de pellets está disponível on line
(https://goo.gl/pBcWzX), pode ser acessado via smartphones e sua interatividade se dá por meio das rotas que podem ser criadas para descobrir a que distância está a fábrica de pellets mais próxima. É uma ferramenta que contribui com o desenvolvimento do mercado interno porque apresenta todos os produtores do biocombustível aos consumidores e desenvolvedores de equipamentos movidos à pellets. $\mathrm{O}$ mapa, além de tudo, funciona como uma garantia, dada aos clientes, de fornecimento contínuo do produto em várias regiões do país, podendo ser realizado por vários fornecedores. Uma evidência de sua utilidade para o mercado de biocombustíveis pellets está no número de visualização, que alcançou mais de 53 mil views (Figura 2) desde que foi ao ar pela primeira vez, em janeiro de 2015. 
Com base nesse Mapa dos Produtores de pellets, criado pela apuração dos dados de pesquisa dos formulários, o Brasil possui 18 indústrias fabricantes do produto, distribuídas pelas Regiões Sul e Sudeste do país, nos estados de Minas Gerais (MG), São Paulo (SP), Paraná (PR), Santa Catarina (SC) e Rio Grande do Sul (RS).

Esses dados são maiores do que o relatado por Welfle (2017) e Garcia et al. (2017), que apontaram a existência de 10 e 13 empresas fabricantes no país em 2016, respectivamente. Portanto, houve um aumento do número de fabricantes de pellets e esses autores relatam que a expansão deste mercado, no Brasil e no Mundo, é explicada pela crescente demanda por fontes de energia renovável que sejam alternativas ao petróleo e seus derivados, pois estes emitem gases do efeito estufa que contribuem com o aquecimento global.

Quanto à produção dos biocombustíveis pellets, é possível concluir que ela aumentou 3,47 vezes de 2016 para 2017, conforme pode-se observar na Tabela 1 . O crescimento acentuado da produção é justificado pelo maior volume de pellets de madeira destinados ao mercado exportação. Em 2016, 51,71\% da produção foi destinada à este mercado externo, para uso em aquecimento residencial, sobretudo no continente europeu. Para o ano de 2017, cerca de $66 \%$ da produção brasileira de pellets foi destinada para esses clientes, principalmente Reino Unido e Itália. No entanto, apesar do crescimento da produção, a participação do Brasil no mercado internacional ainda é pouco significativa e representa menos de $1 \%$ do total, segundo Garcia et al (2017).

Tabela 1. Evolução da produção de pellets de biomassa vegetal no Brasil.

\begin{tabular}{ccc}
\hline Ano & Produção (toneladas por ano) & Referências Bibliográficas \\
\hline 2015 & 75.000 & Garcia et al., 2017. \\
2016 & 135.350 & Garcia, 2017. \\
2017 & 470.000 & Este trabalho \\
\hline
\end{tabular}

De acordo com as informações apuradas dos formulários (Tabela 2), 15 empresas utilizam os resíduos de pinus (na forma de serragem, pó de serra ou maravalha) das indústrias madeireiras como principal matéria-prima do processo de peletização. Uma empresa do interior de São Paulo relatou usar o bagaço de cana-de-açúcar, outra indústria do Rio Grande do Sul disse utilizar a madeira da acácia-negra (Acacia mearnsii) e um fabricante de Minas Gerais confirmou que produz pellets com a casca do café (evidenciado na literatura por Faria et al., 2016). Esse último material residual é a epiderme do grão de café, que é uma película prateada que envolve a semente.

A escolha da matéria-prima para a produção dos pellets está relacionada à disponibilidade de biomassa agroflorestal residual próximo à planta industrial. Os resíduos de pinus, utilizado por mais de
$83 \%$ dos produtores atuais, são subprodutos das indústrias madeireiras da região onde as fábricas estão localizadas (GARCIA et al., 2017). Além disso, a baixa densidade à granel desses materiais lignocelulósicos se traduzem em alto custo de transporte, inviabilizando o projeto de indústria de pellets se o material encontrarse a mais de $200 \mathrm{~km}$ de raio da fábrica (GARCIA et al., 2016b).

Embora Welfle (2017) tenha apontado o eucalipto como matéria-prima utilizada pelas indústrias de pellets brasileiras, isso não se confirmou nessa pesquisa exploratória. Nenhum fabricante de pellets citou que utiliza essa matériaprima na sua produção industrial.

Os resíduos da madeira de eucalipto são preteridos pelos produtores porque esse material lignocelulósico é mais denso e tem maior dureza do que o pinus, causando excessivos desgastes nas 
matrizes de peletização e elevando os custos de produção (GARCIA et al., 2017).

O Brasil possui ampla variedade de biomassas vegetais, que podem ser compactadas na forma de pellets, para fins energéticos. Há relatos na literatura de pellets de ponteira de eucalipto (PINTO et al., 2015), pellets de eucalipto (PEREIRA et al., 2016), pellets de bambu (SETTE JR et al., 2016), pellets de capim-elefante (GARCIA et al., 2016b) e até misturas de materiais lignocelulósicos $(70 \%$ de pinus com $30 \%$ de eucalipto), que tem o objetivo de facilitar o processo de densificação e minimizar os desgastes mecânicos na matriz perfurada de peletização (GARCIA et al., 2017; SCATOLINO et al., 2017). No entanto, são estudos laboratoriais que buscam conhecer as características mais relevantes dessas biomassas vegetais para uso energético, mas ainda não se trata de produção em escala industrial.

Tabela 2. Quantidade de indústrias e produção de pellets no Brasil, em 2017.

\begin{tabular}{ccccc}
\hline \multirow{2}{*}{ Biomassa vegetal } & \multicolumn{2}{c}{ Indústrias de pellets } & \multicolumn{2}{c}{ Produção de pellets } \\
& Quantidade & $\%$ & Toneladas & $\%$ \\
\hline Acácia-negra & 1 & 5,56 & 215.000 & 45,75 \\
Bagaço de cana-de-açúcar & 1 & 5,56 & 5.300 & 1,13 \\
Casca-de-café & 1 & 5,56 & 100 & 0,02 \\
Pinus & 15 & 83,33 & 249.600 & 53,11 \\
\hline TOTAL & 18 & 100 & 470.000 & 100 \\
\hline
\end{tabular}

\section{CONCLUSÕES}

Este trabalho de pesquisa centrou-se na criação de um mapa dos produtores de biocombustíveis pellets no Brasil. A partir das análises dos formulários enviados aos produtores, conclui-se que:

- O Brasil possui 18 indústrias ativas na produção de biocombustíveis pellets;

- Somente 4 tipos de material lignocelulósico são utilizados pelos

\section{REFERÊNCIAS}

CHRISTOFOROU, E. A.; FOKAIDES, P. A. Thermochemical properties of pellets derived from agro-residues and the wood industry. Waste and Biomass Valorization, v. 8 (4): 1325-1330, 2017.

FARIA, W. S.; PROTÁSIO, T. P.; TRUGILHO, P.F.; CARNEIRO, A.C.O. ; ANDRADE, C. R.; GUIMARÃES JUNIOR, J. B. Transformação dos resíduos lignocelulósicos da cafeicultura em pellets para geração de energia térmica. Coffee Science, v. 11 (1): 137-147, 2016.

GARCIA, D.P. Cresce a produção de pellets no brasil. O Papel, v.78 (9): 72-73, 2017. produtores de pellets brasileiros: pinus, acácia-negra, bagaço de cana-de-açúcar e casca de café;

- O Brasil produziu, em 2017, 470.000 toneladas de pellets, sendo a maior parte de pellets de pinus $(53,11 \%)$ seguido pelos pellets de Acácia-negra $(45,75 \%)$.

GARCIA， D. P.; CARASCHI， J. C.; VENTORIM, G.; VIEIRA, F. H. A. Trends and challenges of Brazilian pellets industry originated from agroforestry. Cerne, v. 22 (3): 233-240, 2016 a.

GARCIA， D. P.; CARASCHI, J. C.; VENTORIM, G. Decomposição térmica de pellets de madeira por TGA. Holos, v. 1 (32): 327-339, $2016 b$.

GARCIA, D. P.; CARASCHI, J. C.; VENTORIM, G. O setor de pellets de madeira no Brasil. Ciência da Madeira, v. 8 (1): 21-28, 2017.

GARCIA， D. P.; CARASCHI, J. C.; VENTORIM, G.; VIEIRA, F. H. A.; 
PROTÁSIO, T.P. Comparative energy properties of torrefied pellets in relation to pine and elephant grass pellets. Bioresources, v.13 (2): 2898-2906, 2018.

HEIDEMANN, L. A.; OLIVEIRA, A. M. M.; VEIT, E. A. Ferramentas on line no ensino de ciências: uma proposta com o Google Docs. Física na escola, v. 11 (2): 30-33, 2010.

HSU, F. M.; LIN, Y. T.; HO, T. K. Design and implementation of an intelligent recommendation system for tourist attractions: The integration of EBM model, Bayesian network and Google Maps. Expert Systems with Applications, v. 39 (3): 3257-3264, 2012.

HU, S.; DAI, T. Online map application development using Google Maps API, SQL database, and ASP .NET. International Journal of Information and Communication Techonology Research, v. 3 (3): 102-110, 2013.

PEREIRA, B. L. C. ; CARNEIRO, A. C. O.; CARVALHO, A. M. M. L.; VITAL, B. R.; OLIVEIRA, A. C.; CANAL, W. D. Influência da adição de lignina kraft nas propriedades de pellets de eucalipto. Floresta, v. 46 (2): 235-242, 2016.

PINTO, A. A. S.; PEREIRA, B. L. C.; CÂNDIDO, E. L.; OLIVEIRA, A. C.; CARNEIRO, A. C. O.; CARVALHO, A. M. M. L. Caracterização de pellets de ponteira de eucalipto. Ciência da Madeira, v. 6 (3): 232-236, 2015.

SCATOLINO, M. V.; CABRAL NETO, L. F.; T. P.; TRUGILHO, P. F.; CARNEIRO, A.C.O.; ANDRADE, C. R.; GUIMARÃES JÚNIOR, J. B.; MENDES, L. M. Options for generation of sustainable energy: production of pellets based on combinations between lignocellulosic biomasses. Waste and Biomass Valorization, v. 8 (39): 1-11, 2017.

SETTE JUNIOR, C. R.; FREITAS, P. C.; FREITAS, V. P.; YAMAJI, F. M.; ALMEIDA, R. A. A. Production and characterization of bamboo pellets. Bioscience Journal, v. 32 (4): 922-930, 2016.
SILVA, A. P. A.; CHAVES, J. M. Utilização do Google Maps e Google Earth no ensino médio: estudo de caso no Colégio Estadual da Polícia Militar-Diva Portela em Feira de Santana-BA. Anais XV Simpósio Brasileiro de Sensoriamento Remoto, v. 1 (1): 32203226, 2011.

SPANHOL, A.; NONES, D. L.; KUMABE, F. J. B.; BRAND, M. A. Qualidade dos pellets de biomassa florestal produzidos em Santa Catarina para a geração de energia. Floresta, v. 45 (4): 833-843, 2015.

TAVARES, M. A. M. E.; TAVARES, S. R. L. Perspectivas para a participação do Brasil no mercado Internacional de pellets. Holos, v. 5 (31): 292-306, 2015.

THRÄN, D.; PEETZ, D.; SCHAUBACH, $\mathrm{K}$. Global wood pellet industry and trade study 2017. Austria: IEA Bioenergy - Task 40, 2017.

WELFLE, A. Balancing growing global bioenergy resource demands - Brazil's biomass potential and the availability of resources for trade. Biomass \& Bioenergy, v. 105 (6): 83-95, 2017. 